OPEN

SUBJECT AREAS:

BIOPHYSICAL CHEMISTRY

ELECTROCATALYSIS

Received

28 August 2013

Accepted

25 November 2013

Published

16 December 2013

Correspondence and requests for materials should be addressed to H.F.L. (liuhf@mail.hust. edu.cn); Y.L.G. Iguoyunlong@iccas. ac.cn);J.R.G. (gongir@

nanoctr.cn) or S.W.

(chmsamuel@mail.

hust.edu.cn)

\section{One-Pot Microbial Method to Synthesize Dual-Doped Graphene and Its Use as High-Performance Electrocatalyst}

Peipei Guo' , Fei Xiao' , Qian Liư ${ }^{3}$, Hongfang Liu' ', Yunlong Guo², Jian Ru Gong 3 , Shuai Wang' \& Yunqi Liu²

'School of Chemistry \& Chemical Engineering, Huazhong University of Science and Technology, Wuhan, 430074, P. R. China, ${ }^{2}$ Beijing National Laboratory for Molecular Sciences, Institute of Chemistry, Chinese Academy of Sciences, Beijing 100190, P. R. China, ${ }^{3}$ National Center for Nanoscience and Technology, China (NCNST), 11 Zhongguancun Beiyitiao, Beijing 100190, P. R. China.

A novel strategy to synthesize nitrogen $(\mathrm{N})$ and sulfur (S)-doped graphene $(\mathrm{G})$ is developed through sulfate-reducing bacteria treating graphene oxide (GO). The N, S-doped G demonstrates significantly improved electrocatalytic properties and electrochemical sensing performances in comparison with single-doped graphene due to the synergistic effects of dual dopants on the properties of graphene.

raphene has hold a great promise for its potential applications in electrochemistry due to its large theoretical specific surface area $\left(2620 \mathrm{~m}^{2} \mathrm{~g}^{-1}\right)$, excellent electrical conductivity and high electrocatalytic activities $^{1,2}$. Particularly, it has been recognized that the doping of heteroatoms into graphene is an efficient method to enhance its electrocatalytic performances ${ }^{3}$. Both theoretical calculations and experimental results have proved that the introduction of more electronegative nitrogen $(\mathrm{N})$ atoms into $\mathrm{sp}^{2}$ hybridized carbon (C) frameworks in graphene is generally effective in modifying their electrical properties and chemical activities. For instance, the spin density and charge distribution of $\mathrm{C}$ atom will be influenced by the neighbor $\mathrm{N}$ dopants $\mathrm{s}^{5,6}$, inducing the "activation region" on graphene surface, which is expected to directly participate in catalytic reactions, and/or provide more nucleation sites to anchor the catalytically active metal nanoparticles ${ }^{7}$. Recent findings have also shown that the doping of sulfur $(S)$ atom into the graphene materials caused the changed spin density of graphene, which resulted in the excellent catalytic activity, long-term stability, and high tolerance in alkaline media of the S-doped graphene (S-G) for oxygen reduction reaction (ORR) $)^{7,8}$. Furthermore, N, S-doped graphene $(\mathrm{N}, \mathrm{S}-\mathrm{G})$ had been realized and demonstrated excellent catalytic activity ${ }^{9}$. Although great progresses have been made in the synthesis of different types of doped graphene materials, these approaches require high temperature $\left(900{ }^{\circ} \mathrm{C}\right)$ treatment and toxic chemical (i.e., THF) ${ }^{3-9}$. Therefore, low-temperature and facile approaches are highly desired for the large-scale production of doped graphene materials with excellent catalytic performances.

In this work, we report for the first time a novel approach to synthesize N, S-G through a one-pot reduction of GO by microbial respiration of sulfate-reducing bacteria (SRB) under the mild conditions $\left(37^{\circ} \mathrm{C}\right)$ and its promising applications as high-performance electrocatalysts for the electrochemical sensing of heavy metal ions. SRB, a diverse group of heterotrophic and mixotrophic bacteria ${ }^{10}$, is ubiquitous in marine sediments ${ }^{11-14}$, hydrothermal vents ${ }^{15}$, waste landfills and even in the human body such as mouth ${ }^{16,17}$ and bowel ${ }^{18}$, and plays an important role in the global cycling of $\mathrm{C}$ and $\mathrm{S}$. These microbes mainly use $\mathrm{S}$ as a terminal electron acceptor for the degradation of organisms during anaerobic respiration ${ }^{19}$. Considering that graphene oxide (GO) has shown the property as electron acceptor ${ }^{20-24}$, it is possible to realize the reduction of GO by microbial respiration of SRB. Our findings have shown that N, S-G could be obtained through sulfate-reducing bacteria treating GO and exhibited high electrocatalytic activity towards the reduction of heavy metal ions such as cadmium ion $\left(\mathrm{Cd}^{2+}\right)$ and lead ion $\left(\mathrm{Pb}^{2+}\right)$. We also fabricated an electrochemical sensing platform for ultrasensitive simultaneous determination of $\mathrm{Cd}^{2+}$ and $\mathrm{Pb}^{2+}$ with N, S-G as electrocatalyst. This study not only gives insight into the synergistic effect of multielement dopants on the properties of graphene, but also opens the possibility of developing new types of graphene-based functional materials with excellent electrochemical properties by a facile and low-temperature approach. 


\section{Results}

The synthetic route of N, S-G is described in Fig. 1A. The microbial reduction is initiated by mixing GO dispersion with SRB and fresh culture medium $^{25}$, and the mixture is then incubated under an anaerobic condition in constant temperature incubator $\left(37^{\circ} \mathrm{C}\right)$. After that, the color of GO dispersion changes from brown to black (Fig. 1A), indicative of the restoration of $\mathrm{sp}^{2}$ carbon sites and re-establishment of the electronic conjugation network. The transmission electron microscope (TEM) image shows that N, S-G maintains a monolayer and flexible structure (Fig. 1B). The reduction degree of GO is monitored by time-dependent UV-vis spectroscopy. As shown in Fig. 1C, with increase of reaction time, the UV-vis absorption peak of GO dispersion at $231 \mathrm{~nm}$ corresponding to $\pi \rightarrow \pi^{*}$ transitions of aromatic $\mathrm{C}=\mathrm{C}$ bonds gradually shifts to $267 \mathrm{~nm}$ after microbial reduction treatment at $37^{\circ} \mathrm{C}$ for 6 days. The absorption peak in the full spectral region increases with reaction time and keeps almost unchanged after the sixth day (Fig. S2), demonstrating the completion of microbial reduction of GO.

Fig. 1D are the Fourier Transform Infrared (FT-IR) spectra of GO and $\mathrm{N}, \mathrm{S}-\mathrm{G}$. The spectrum of $\mathrm{GO}$ shows the presence of $\mathrm{C}-\mathrm{O}$ (v (epoxy or alkoxy)) at $1069 \mathrm{~cm}^{-1}, \mathrm{C}-\mathrm{OH}$ (v (carboxyl)) at $1398 \mathrm{~cm}^{-1}, \mathrm{C}=\mathrm{C}$ at $1621 \mathrm{~cm}^{-1}$, and $\mathrm{C}=\mathrm{O}$ in carboxylic acid and carbonyl moieties (v (carbonyl)) at $1725 \mathrm{~cm}^{-1}$, respectively. After bacteria treatment, the adsorption bands of oxygen functionalities disappear, and only the peak of $\mathrm{C}=\mathrm{C}$ remains, suggesting that $\mathrm{GO}$ has been effectively reduced ${ }^{26}$. The thermal stability of N, S-G examined by thermal gravimetric analysis (TGA) also proves the removal of thermally labile oxygen functional groups by the microbial reduction (Fig. S3). Fig. 1E shows the Raman spectra of GO and N, S-G. The spectrum of GO displays two prominent peaks at 1349 and $1599 \mathrm{~cm}^{-1}$, corresponding to the well-documented D and G bands, respectively. The intensity ratio of $\mathrm{D}$ band to $\mathrm{G}$ band $\left(\mathrm{I}_{\mathrm{D}} / \mathrm{I}_{\mathrm{G}}\right)$ of $\mathrm{GO}$ is about 1.02. The G band of N, S-G shifts to $1586 \mathrm{~cm}^{-1}$, and its $\mathrm{I}_{\mathrm{D}} / \mathrm{I}_{\mathrm{G}}$ increases to 1.40 due to the defects introduced by $\mathrm{N}$ and $\mathrm{S}$ dually doping and the realization of deoxygenation of $\mathrm{GO}^{27}$.

$\mathrm{X}$-ray photoemission (XPS) is a powerful tool to identify the surface chemical composition and the valence state in bulk material ${ }^{28}$. The full range XPS analysis of N, S-G shows the presence of $\mathrm{C}, \mathrm{O}, \mathrm{N}$ and $\mathrm{S}$ (Fig. 2A) ${ }^{29}$. The degree of GO reduction is described via the atomic ratio of carbon and oxygen $(\mathrm{C} / \mathrm{O})$ obtained by taking the ratio

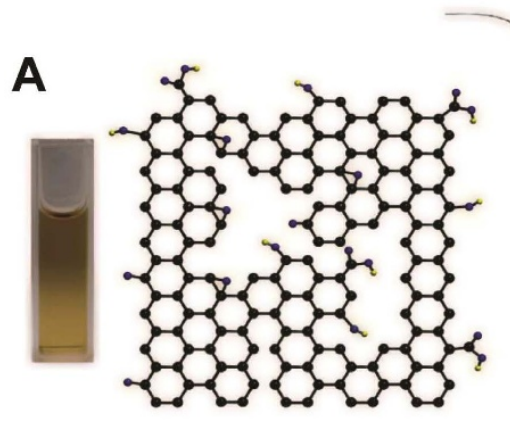

$\mathrm{GO}$
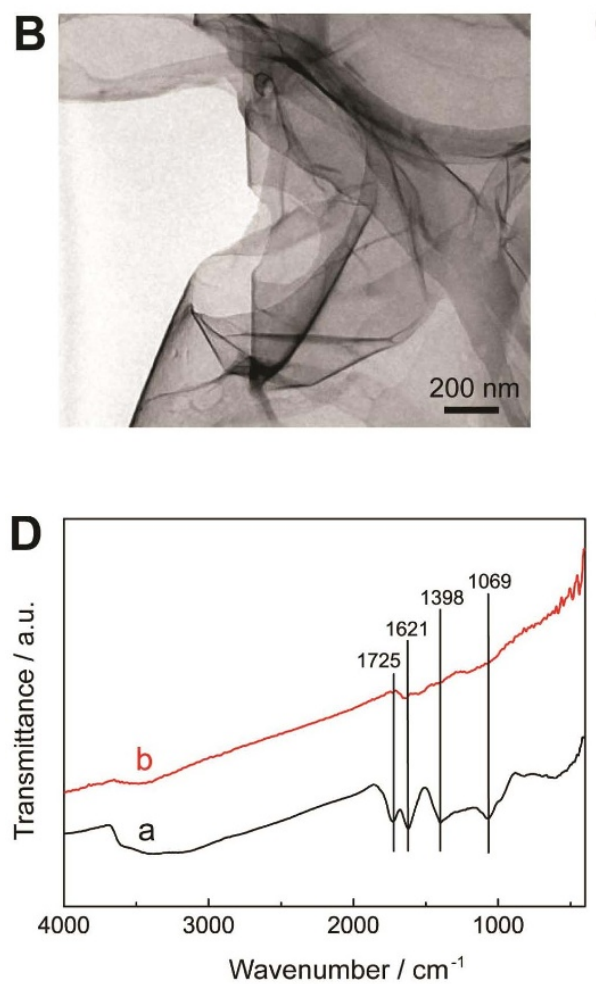

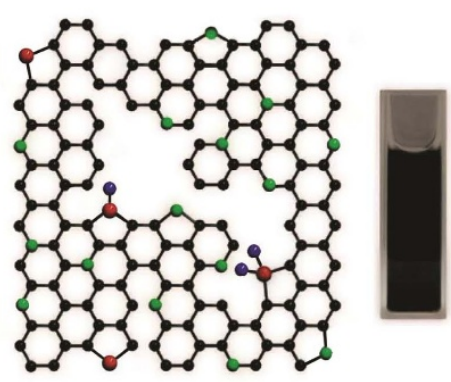

N, S-G
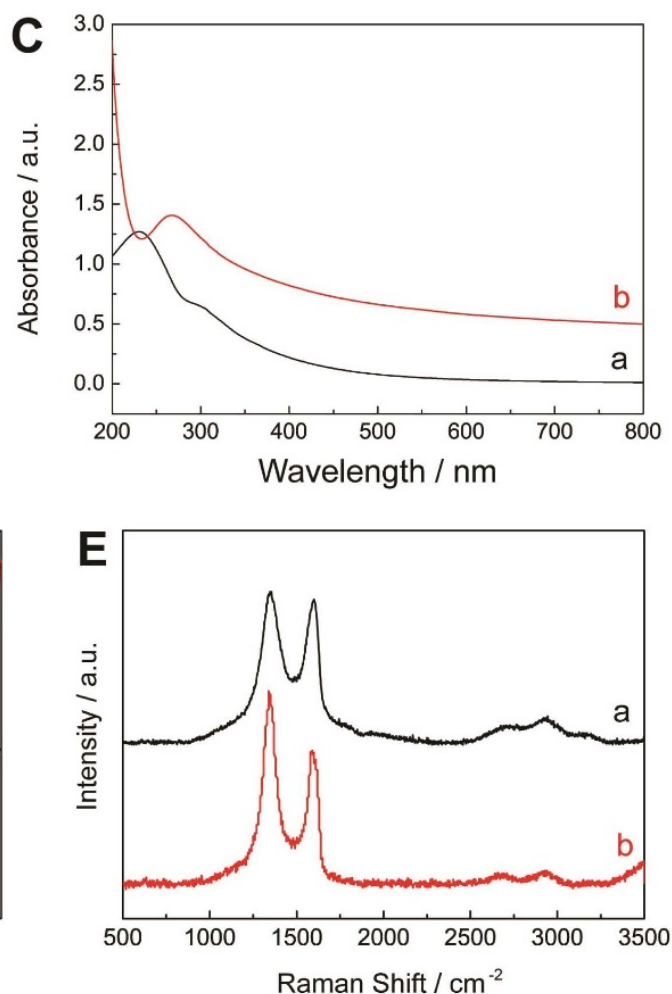

Figure $1 \mid$ (A) Schematic illustration of the formation of N, S-G by one-pot microbial reduction process. (B) TEM image of N, S-G. (C) UV-vis absorption spectra of GO aqueous dispersion before (a) and after (b) reduction. (D) FT-IR spectra and (E) Raman spectra of GO (a) and N, S-G (b), respectively. 
of $\mathrm{C} 1 \mathrm{~s}$ to $\mathrm{O} 1 \mathrm{~s}$ peak areas in XPS spectra. After microbial reduction, the $\mathrm{C} / \mathrm{O}$ increases from 2.12 to $4.02^{29-31}$. Moreover, the intensity of $\mathrm{C}-\mathrm{O} / \mathrm{C}-\mathrm{O}-\mathrm{C}$ peak decreases and the $\mathrm{C}-\mathrm{C} \mathrm{sp}^{2}$ bond becomes predominant (Fig. S4), indicating that most of the oxygen-containing functional groups are removed and the conjugated graphene networks are restored. The XPS analysis also confirms the successful doping of $\mathrm{N}$ and $\mathrm{S}$ atoms into the graphene networks as well ${ }^{29}$. The high resolution XPS spectrum of $\mathrm{N}$ 1s (Fig. 2B) reveals the presence of three nitrogen functional groups, and an atomic percentage of doped nitrogen to be about $6.11 \%$. Three nitrogen peaks are observed for pyridinic $\mathrm{N}$, pyrrolic $\mathrm{N}$ and graphitic $\mathrm{N}$ with binding energies of $400.01 \mathrm{eV}, 401.45 \mathrm{eV}$ and $402.50 \mathrm{eV}$, respectively. Among these nitrogen configurations, the pyridinic $\mathrm{N}$ is the main form, which is believed to enhance the electrochemical properties of $\mathrm{N}$-doped graphene $^{32}$. Moreover, the binding energies of $S 2 p$ are also used to analyze the $\mathrm{S}$ doping in synthesized graphene (Fig. 2C). The peaks at $164.02 \mathrm{eV}$ and $167.92 \mathrm{eV}$ suggest the doping in the form of sulfide bonds (-C-S-C-, 78\%) and oxidized sulfur bonds (-C-SO-C- or -C$\mathrm{SO}_{2}$-C-, 22\%), respectively ${ }^{8,33}$. The calculated doping concentration of sulfur is $1.1 \%$ (atom \%).

\section{Discussion}

Considering the unique doped structure ${ }^{8,32}, \mathrm{~N}, \mathrm{~S}-\mathrm{G}$ is expected to possess excellent electrochemical properties ${ }^{34-39}$. In this work, the as-synthesized N, S-G has been applied to fabricate a highly sensitive electrochemical platform to determine trace $\mathrm{Cd}^{2+}$ and $\mathrm{Pb}^{2+}$ by differential pulse anodic stripping voltammetry (DPASV). For the fabrication of modified electrodes, $2 \mathrm{~mL}$ of a $0.1 \%$ Nafion ethanol solution was added into $2 \mathrm{ml}$ of a $1.0 \mathrm{mg} / \mathrm{mL} \mathrm{N}, \mathrm{S}-\mathrm{G}$ dispersion to give an uniform (N, S-G)-Nafion suspension. Then $5 \mu \mathrm{L}$ suspension was dropped onto a clean glass carbon electrode (GCE) to form (N,S$\mathrm{G})$-Nafion modified GCE ((N,S-G)-Nafion/GCE). The Bi film coated (N,S-G)-Nafion/GCE (Bi/(N,S-G)-Nafion/GCE) was fabricated by electrodepositing $\mathrm{Bi}$ on $(\mathrm{N}, \mathrm{S}-\mathrm{G})-\mathrm{Nafion} / \mathrm{GCE}$ using $\mathrm{Bi}\left(\mathrm{NO}_{3}\right)_{3}$ solution at $-1.2 \mathrm{~V}$ for $300 \mathrm{~s}$ (Fig. S5). Compared with the bare GCE and Nafion modified GCE (Nafion/GCE) which show distorted peaks and small peak currents of metals, both of Bi/GCE and (N,S-G)-Nafion/GCE demonstrated enhanced response signals due to efficient metal deposition (Fig. 3A ${ }^{40}$. Furthermore, welldefined reduction peaks with the largest peak currents for target metal ions were obtained at $\mathrm{Bi} /(\mathrm{N}, \mathrm{S}-\mathrm{G})-\mathrm{Nafion} / \mathrm{GCE}$ due to the synergistic effect of Bi film and N, S-G.

The resulting calibration plots are linear over the range from 9.0 to $30.0 \mu \mathrm{g} \mathrm{L}-1$ for the simultaneous determination of $\mathrm{Pb}^{2+}$ and $\mathrm{Cd}^{2+}$ (Fig. 3B). The DPASVs of $\mathrm{Pb}^{2+}$ and $\mathrm{Cd}^{2+}$ with different concentrations on $\mathrm{Bi} /(\mathrm{N}, \mathrm{S}-\mathrm{G})-\mathrm{Nafion} / \mathrm{GCE}$ are illustrated in Fig. 3C. The Bi/ (N,S-G)-Nafion/GCE demonstrates excellent sensitivity and selectivity. The detection limits are $0.016 \mu \mathrm{g} \mathrm{L}^{-1}$ for $\mathrm{Cd}^{2+}$ and $0.018 \mu \mathrm{g} \mathrm{L}^{-1}$ for $\mathrm{Pb}^{2+}$, respectively, which are lower than previously reported results (Table $\mathrm{S} 1$ ).

In order to demonstrate the advantages of $\mathrm{N}, \mathrm{S}-\mathrm{G}$, chemically reduced GO, N-doped graphene (N-G) and S-G were also synthesized (Supporting Information (SI)), and $\mathrm{Bi} / \mathrm{rGO}-\mathrm{Nafion} / \mathrm{GCE}, \mathrm{Bi} /$ (N-G)-Nafion/GCE) and Bi/(S-G)-Nafion/GCE electrodes were also prepared under the similar procedure as that of $\mathrm{Bi} /(\mathrm{N}, \mathrm{S}-\mathrm{G})-\mathrm{Nafion} /$ GCE. The DPASV characteristics of different electrodes show that heteroatom $(\mathrm{N}$ or $\mathrm{S}$ ) doping into graphene leads to more intensive peak current of $\mathrm{Pb}^{2+}$ and $\mathrm{Cd}^{2+}$ on $\mathrm{Bi} /(\mathrm{N}-\mathrm{G})-\mathrm{Nafion} / \mathrm{GCE}$ or $\mathrm{Bi} /(\mathrm{S}-$ $\mathrm{G})$-Nafion/GCE than that on Bi/rGO-Nafion/GCE (Fig. 3D).More importantly, compared with $\mathrm{Bi} /(\mathrm{N}-\mathrm{G})-\mathrm{Nafion} / \mathrm{GCE}$ or $\mathrm{Bi} /(\mathrm{S}-\mathrm{G})$ Nafion/GCE, Bi/(N, S-G)-Nafion/GCE shows enhanced electrochemical signals by about $36 \%$ or $23 \%$ for $\mathrm{Pb}^{2+}$, and $110 \%$ or $91 \%$ for $\mathrm{Cd}^{2+}$, respectively. The signal enhancement should be attributed to $\mathrm{N}$ and $\mathrm{S}$ atoms doped into the carbon lattice of graphene. The electrical conductivity measurement shows that the electrical conductivity of GO and $\mathrm{N}-$, S-doped GO are $1 \times 10^{-4}$ and $2.8 \mathrm{~S} / \mathrm{m}$, respectively. Therefore, we think that $\mathrm{N}$-doping causes an atomicscale structural deformation, and $\mathrm{N}$ atom can act as an electron donor that increases the n-type conductivity of graphite structure ${ }^{41,42}$. Moreover, $\mathrm{S}$ atom has a close electroneutrality to $\mathrm{C}$ atom and the C-S bonds are predominately at the edge or the defect sites, which causes the activity enhancement due to the changed spin density and charge
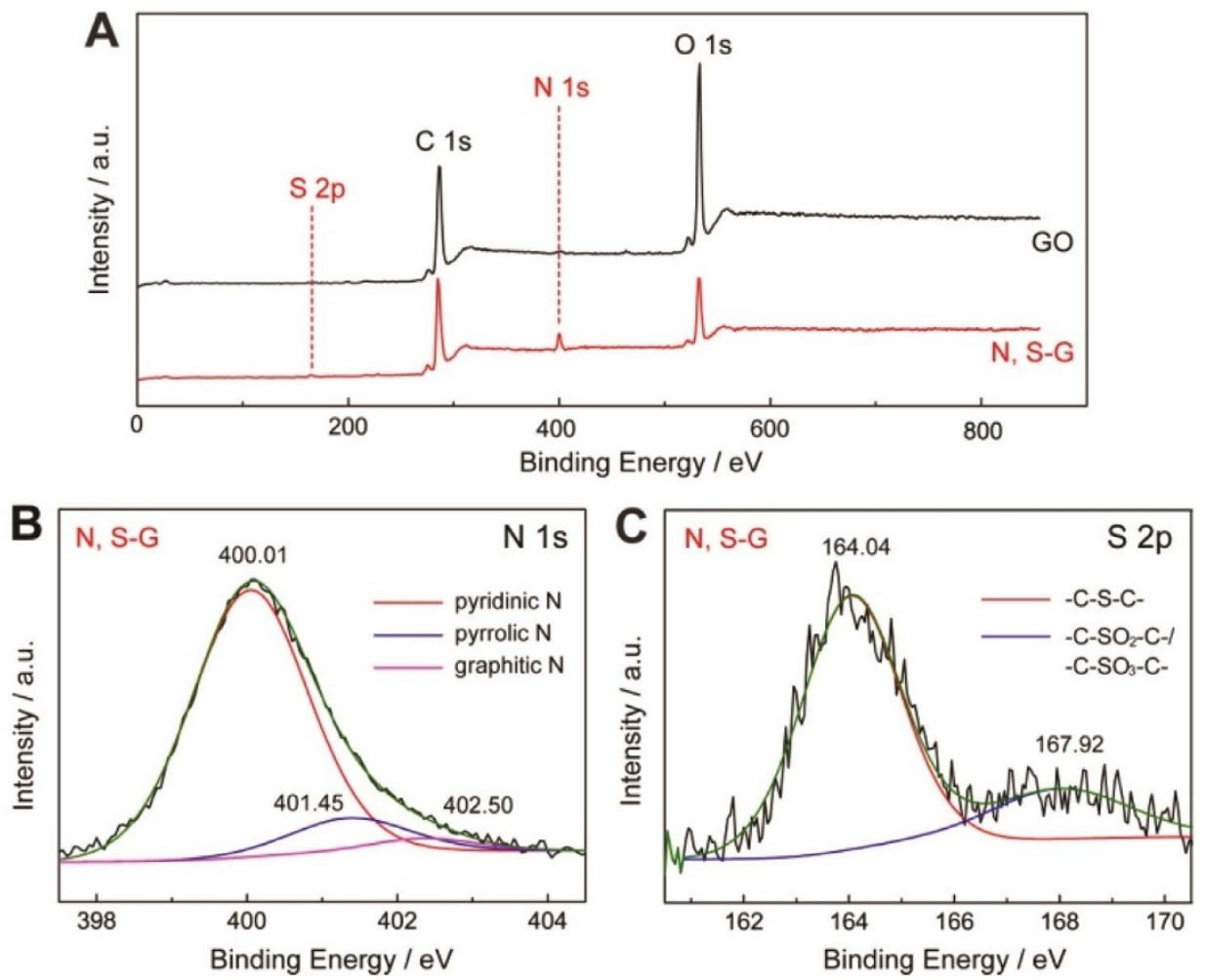

Figure 2 (A) XPS survey spectrum of GO and N, S-G. (B) Curve fit of N 1s spectrum of N, S-G, (C) Curve fit of S 2p spectrum of N, S-G. 

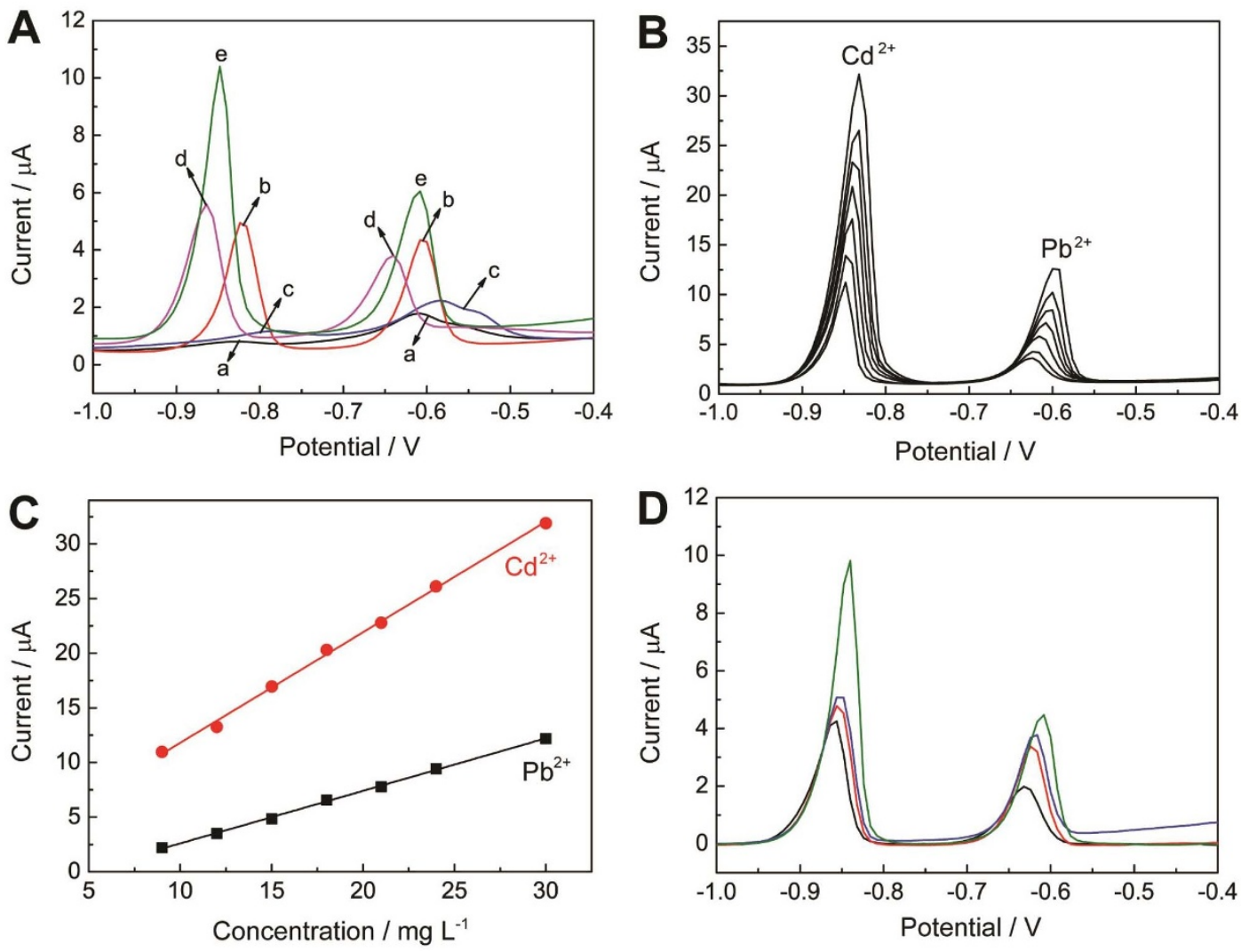

Figure 3 (A) DPASV of $15 \mu \mathrm{g} \mathrm{L}{ }^{-1}$ of $\mathrm{Cd}^{2+}$ and $\mathrm{Pb}^{2+}$ on (a) GCE, (b) Bi/GCE, (c) Nafion/GCE, (d) (N, S-G)-Nafion/GCE and (e) Bi/(N, S-G)-Nafion/ GCE. (B) DPASV of simultaneous analysis of $\mathrm{Pb}^{2+}$ and $\mathrm{Cd}^{2+}$ with concentrations of 30,24,18,15, 12 and $9 \mu \mathrm{L}^{-1}$, respectively. (C) The calibration curve of $\mathrm{Cd}^{2+}$ and $\mathrm{Pb}^{2+}$, respectively. Supporting electrolyte: $0.2 \mathrm{M}$ acetate buffer ( $\mathrm{pH}$ 4.6), deposition potential: $-1.2 \mathrm{~V}$, deposition time: $300 \mathrm{~s}$. (D) DPASV of $15 \mu \mathrm{g} \mathrm{L}^{-1}$ of $\mathrm{Cd}^{2+}$ and $\mathrm{Pb}^{2+}$ on rGO-Nafion/GCE, Bi/(S-G)-Nafion/GCE, Bi/(N-G)-Nafion/GCE, and Bi/(N, S-G)-Nafion/GCE (from bottom to upper).

distribution ${ }^{8}$. Hence, the multi-element doping leads to the greatly enhanced electrocatalytic activity and electrochemical sensing performances.

In summary, we report a one-pot strategy to synthesize a new type of graphene material doped with both $\mathrm{N}$ and $\mathrm{S}$ atoms through the microbial reduction of GO by SRB. The N, S-doped G demonstrated significantly improved electrocatalytic properties and electrochemical sensing performances in comparison with single-doped graphene due to the synergistic effects of dual dopants. For the simultaneous determination of $\mathrm{Cd}^{2+}$ and $\mathrm{Pb}^{2+}$, the $\mathrm{N}, \mathrm{S}-\mathrm{G}$ takes several advantages such as high sensitivity and selectivity, wide linear range and low detection limit. These results are significant because they not only give insight into the synergistic effect of multi-element dopants on the properties of graphene, but also open a way to develop new graphene functional materials with excellent electrochemical property by a simple, economical and environmentally friendly approach.

\section{Methods}

Bacterial cultures. The strain of SRB was isolated by the following procedure. Moist oily soil from Shengli oilfield of China was added to API-RP38 culture medium, and cultivated for $48 \mathrm{~h}$ until the medium turned black. The supernatant solution was then inoculated in fresh medium. This procedure was repeated for several times. The isolated SRB was light yellow under anaerobic conditions at $37^{\circ} \mathrm{C}$ in the culture medium.

The API-RP38 culture medium in the experiment contained (per liter of ultrapure water $^{24}: 4.0 \mathrm{~mL}$ sodium lactate, 1.0 g yeast extract, $0.2 \mathrm{~g}$ magnesium sulfate $\left(\mathrm{MgSO}_{4} \cdot 7 \mathrm{H}_{2} \mathrm{O}\right), 0.1 \mathrm{~g}$ vitamin $\mathrm{C}(\mathrm{Vc}), 0.01 \mathrm{~g}$ potassium diphosphate $\left(\mathrm{K}_{2} \mathrm{HPO}_{4}\right)$ and $10.0 \mathrm{~g}$ sodium chloride $(\mathrm{NaCl})$. The $\mathrm{pH}$ was adjusted to $7.0 \sim 7.2$ by the appropriate addition of $1 \mathrm{M}$ sodium hydroxide $(\mathrm{NaOH})$. The solution was sterilized with an autoclave at $121^{\circ} \mathrm{C}$ for $20 \mathrm{~min}$ and then cooled to room temperature. After cooling,
$0.2 \mathrm{~g} \mathrm{FeSO}_{4} \cdot(\mathrm{NH} 4)_{2} \mathrm{SO}_{4} \cdot 6 \mathrm{H}_{2} \mathrm{O}$ sterilized using ultraviolet light was added to the solution.

Microbial reduction of GO. The microbial reduction was initiated by mixing $100 \mathrm{~mL}$ of as-prepared GO solution $\left(0.1 \mathrm{mg} \cdot \mathrm{mL}^{-1}\right)$ aseptically with $20 \mathrm{~mL}$ culture of sulfatereducing bacteria and $30 \mathrm{~mL}$ fresh culture medium. The mixture was incubated in anaerobic conditions at $37^{\circ} \mathrm{C}$ constant temperature incubator for several days. The resulting stable black dispersion was centrifuged $(14000 \mathrm{rpm}$ ) and washed with $1 \mathrm{M}$ $\mathrm{HCl}$ aqueous solution to remove the organic matter, cell debris and ultrapure water for several times, respectively. Finally, the resulting solid was dried at $80{ }^{\circ} \mathrm{C}$ under vacuum.

Preparation of N-G and S-G. For the preparation of N-G, a $10 \mathrm{~mL}$ portion of $2 \mathrm{mg} /$ mL homogeneous GO aqueous dispersion was mixed with $2 \mathrm{~mL}$ ammonia, sealed in a $100-\mathrm{mL}$ Teflon-lined autoclave and then maintained at $180^{\circ} \mathrm{C}$ for $12 \mathrm{~h}$. The autoclave was then naturally cooled to room temperature. The as-prepared graphene materials were taken out and dried at $80{ }^{\circ} \mathrm{C}$ under vacuum for $48 \mathrm{~h}$ to obtain $\mathrm{N}-\mathrm{G}$ with doping concentration of nitrogen about $6.20 \%$ (atom \%). For the preparation of S-G, $0.0404 \mathrm{~g}$ GO and $0.0201 \mathrm{~g}$ benzyl disulfide (BDS) were first ultrasonically dispersed in $50 \mathrm{ml}$ ethanol for about $30 \mathrm{~min}$. The resulting suspension was filtered to obtain uniform thin films. The films were placed into a quartz tube and annealed at $900{ }^{\circ} \mathrm{C}$ in argon atmosphere to obtain S-G with doping concentration of sulfur about 1.1\% (atom \%)2.

Fabrication of the (N, S-G)-Nafion composite film. The GCE was first polished with 0.3 and $0.05 \mu \mathrm{m}$ alumina slurries and rinsed thoroughly with ultrapure water, then sonicated in $1: 1$ ethanol, $1: 1$ nitric acid and ultrapure water for $5 \mathrm{~min}$, respectively, and dried at room temperature. Next, a $2 \mathrm{ml}$ of $1.0 \mathrm{mg} \cdot \mathrm{mL}^{-1} \mathrm{~N}, \mathrm{~S}-\mathrm{G}$ solution was mixed with equal volume of $0.1 \%$ Nafion-ethanol solution by ultrasonication for $15 \mathrm{~min}$ to give $0.50 \mathrm{mg} \cdot \mathrm{mL}^{-1}$ suspension. Finally, an aliquot of $5 \mu \mathrm{L}$ of the mixture was coated on the pretreated GCE electrode and dried at room temperature to obtain (N, S-G)-Nafion/GCE. (N-G)-Nafion, (S-G)-Nafion, and rGO-Nafion composite films were also synthesized under the similar procedure.

Fabrication of Bi/(N, S-G)-Nafion/GCE. The three electrodes were immersed into a $50 \mathrm{~mL}$ electrochemical cell, containing $0.2 \mathrm{~mol} \mathrm{~L}^{-1}$ acetate buffer (pH 4.6), $175 \mu \mathrm{g}$ $\mathrm{L}^{-1} \mathrm{Bi}(\mathrm{III})$ and appropriate target metals. The (N, S-G)-Nafion modified GC 
electrode with Bi film was plated in situ by spiking the sample with the required concentration of $\mathrm{Bi}(\mathrm{III})$ and simultaneously depositing $\mathrm{Bi}^{3+}$ and the target metals on the surface of the electrode at $-1.2 \mathrm{~V}$ under stirring for $300 \mathrm{~s}$. Following the conditioning step, the stirring was stopped and after $10 \mathrm{~s}$ equilibration period, the voltammogram was recorded by applying a positive-going potential scan from -1.2 to $0.2 \mathrm{~V}$ (with a step increment of $8 \mathrm{mV}$, amplitude of $50 \mathrm{mV}$, and pulse period of $0.2 \mathrm{~s})$. Prior to the next cycle, a cleaning step (120 s at $0.3 \mathrm{~V}$, with solution stirring) was used to remove the target metals and bismuth film. Bi/(N-G or S-G or RGO)Nafion/GCE was also synthesized under the similar procedure.

Chemicals and apparatus. Nafion (5 wt\% in low aliphatic alcohols) was purchased from DuPont, and then diluted to $0.1 \mathrm{wt} \%$ Nafion with ethanol. $\mathrm{Cd}\left(\mathrm{NO}_{3}\right)_{2}, \mathrm{~Pb}\left(\mathrm{NO}_{3}\right)_{2}$, $\mathrm{Bi}\left(\mathrm{NO}_{3}\right)_{3}, \mathrm{CH}_{3} \mathrm{COOH}, \mathrm{CH}_{3} \mathrm{COONa}$ were purchased from Shanghai Sinopharm Chemical Reagent Co. Ltd. Benzyl disulfide (BDS) was purchased from Aladdin Chemistry Co. Ltd. All chemicals employed in this work were of analytical reagent grade and used without any further purification. Stock solutions of $\mathrm{Cd}^{2+}$ and $\mathrm{Pb}^{2+}$ were obtained by diluting the corresponding standard stock solutions prepared with $\mathrm{Cd}\left(\mathrm{NO}_{3}\right)_{2}$ and $\mathrm{Pb}\left(\mathrm{NO}_{3}\right)_{2}$ in $1.0 \mathrm{wt} \% \mathrm{HNO}_{3}$, respectively. $\mathrm{Bi}\left(\mathrm{NO}_{3}\right)_{3}$ was used for the Bi film electrode (BiFE) by diluting the corresponding standard stock solution. A $0.2 \mathrm{M}$ acetate buffer ( $\mathrm{pH}$ 4.6) prepared by mixing appropriate amounts of $\mathrm{CH}_{3} \mathrm{COOH}$ and $\mathrm{CH}_{3} \mathrm{COONa}$ was used to prepare the solution of supporting electrolyte. Unless otherwise stated, all solutions were prepared with ultrapure water $(>18 \mathrm{M} \Omega$ ) from an AJF-1001-P system.

Electrodeposition differential pulse anodic stripping voltammetry (DPASV) and electrochemical impedance spectroscopy (EIS) were performed with a CHI 660C electrochemical workstation ( $\mathrm{CH}$ Instrument Company). The working electrodes were electrodes modified by synthesized functional materials, and the auxiliary and reference electrodes were Pt wire and saturated calomel electrode (SCE), respectively. Fourier transform infrared (FT-IR) spectra were obtained on a Fourier Transform InfraRed spectrometer (EQUINOX 55). UV-vis detection was carried out on a Specord 50 UV-vis spectrophotometer (Germany). Thermogravimetric analyze (TGA) of sample was performed on a Pyris1 TGA thermogravimetric analyzer (Perkin-Elmer Thermal Analysis). X-ray diffraction (XRD) data was recorded with Xray diffraction (XRD, X'Pert $\mathrm{PRO}$ ) with $\mathrm{Cu} \mathrm{K} \alpha$ radiation. $\mathrm{X}$-ray photoelec-tron spectroscopy (XPS) analysis was carried on a VG Multilab 2000 X-ray photoelectron spectrometer. SEM images were obtained from a Hitachi S-4800 Field scanning electron microscope (FSEM). TEM images were obtained from a Tecnai G20 transmission electron microscope (TEM).

1. Yogeswaran, U. \& Chen, S. M. A review on the electrochemical sensors and biosensors composed of nanowires as sensing material. Sensors 8, 290-313 (2008).

2. Zhu, Y. et al. Graphene and graphene oxide: synthesis, properties, and applications. Adv. Mater. 22, 3906-3924 (2010).

3. Wei, D. et al. Synthesis of $\mathrm{N}$-doped graphene by chemical vapor deposition and its electrical properties. Nano Lett. 9, 1752-1758 (2009).

4. Liu, H. T., Liu, Y. Q. \& Zhu, D. B. Chemical doping of graphene. J. Mater. Chem. 21, 3335-3345 (2011).

5. Hang, L. P. \& Xia, Z. H. Mechanisms of oxygen reduction reaction on nitrogendoped graphene for fuel cells. J. Phys. Chem. C 115, 11170-11176 (2011).

6. Groves, M. N., Chan, A. S. W., Malardier-Jugroot, C. \& Jugroot, M. Improving platinum catalyst binding energy to graphene through nitrogen doping. Chem. Phys. Lett. 481, 214-219 (2009).

7. Bourlinos, A. B. et al. Graphite oxide-Chemical reduction to graphite and surface modification with primary aliphatic amines and amino acids. Langmuir 19, 6050-6055 (2003).

8. Yang, Z. et al. Sulfur-doped graphene as an efficient metal-free cathode catalyst for oxygen reduction. ACS Nano 6, 205-211 (2012).

9. Liang, J., Jiao, Y., Jaroniec, M. \& Qiao, S. Z. Sulfur and nitrogen dual-doped mesoporous graphene electrocatalyst for oxygen reduction with synergistically enhanced performance. Angew. Chem. Int. Ed. 51, 11496-111500 (2012)

10. Little, B. J., Ray, R. I. \& Pope, R. K. Relationship between corrosion and the biological sulfur cycle: A Review. Corrosion 56, 433-443 (2000).

11. Mussmann, M., Ishii, K., Rabus, R. \& Amann, R. Diversity and vertical distribution of cultured and uncultured deltaproteobacteria in an intertidal mud flat of the eadden sea. Environ. Microbiol. 7, 405-418 (2005).

12. Boschker, H. T. S. et al. Direct linking of microbial populations to specific biogeochemical processes by 13C-labelling of biomarkers. Nature 392, 801-805 (1998)

13. Webster, G. et al. A comparison of stable-isotope probing of DNA and phospholipid fatty acids to study prokaryotic functional fiversity in sulfatereducing marine sediment enrichment slurries. Environ. Microbiol. 8, 1575-1589 (2006).

14. Ravenschlag, K., Sahm, K., Knoblauch, C., Jørgensen, B. B. \& Amann, R. Community structure, cellular rRNA content, and activity of sulfate-reducing bacteria in marine arctic sediments. Appl. Environ. Microbiol. 66, 3592-3602 (2000).

15. Jeanthon, C., L'Haridon, S., Cueff, V., Banta, A., Reysenbach, A.-L. \& Prieur, D. Thermodesulfobacterium Dydrogeniphilum Sp. Nov., A thermophilic, chemolithoautotrophic, sulfate-reducing bacterium isolated from a deep-sea hydrothermal vent at guaymas basin, and emendation of the genus thermodesulfobacterium. Int. J. Syst. Evol. Microbiol. 52, 765-772 (2002).
16. Willis, C. L., Gibson, G. R., Holt, J. \& Allison, C. Negative correlation between oral malodour and numbers and activities of sulphate-reducing bacteria in the human mouth. Arch. Oral. Biol. 44, 665-670 (1999).

17. Langendijk, P. S., Hagemann, J. \& Van der Hoeven, J. S. Sulfate-reducing bacteria in periodontal pockets and in healthy oral sites. J. Clin. Periodontol. 26, 596-599 (1999).

18. McDougall, R., Robson, J., Paterson, D. \& Tee, W. Bacteremia caused by a recently described novel desulfovibrio species. J. Clin. Microbiol. 35, 1805-1808 (1997).

19. Muyzer, G. \& Stams, A. J. M. The ecology and biotechnology of sulphate-reducing bacteria. Nat. Rev. Microbiol. 6, 441-454 (2008).

20. Salas, E. C., Sun, Z. Z., Lüttge, A. \& Tour, J. M. Reduction of graphene oxide via bacterial respiration. ACS Nano 4, 4852-4856 (2010).

21. Wang, G. M., Qian, F., Saltikov, C. W., Jiao, Q. Y. \& Li, Y. Microbial reduction of graphene oxide by shewanella. Nano Res. 4, 563-570 (2011),

22. Jiao, Y. Q. et al. Deciphering the electron transport pathway for graphene oxide reduction by shewanella oneidensis MR-1. J. Bacteriol. 193, 3662-3665 (2011).

23. Akhavan, O. \& Ghaderi, E. Escherichia Coli Bacteria Reduce Graphene Oxide to Bactericidal Graphene in A Self-limiting Manner. Carbon 50, 1853-1860 (2012).

24. Liu, H., Huang, L., Huang, Z. \& Zheng, J. Specification of sulfate reducing bacteria biofilms accumulation effects on corrosion initiation. Mater. Corros 58, 44-48 (2007).

25. Hummers, Jr. \& Offeman Rechard, E. Preparation of graphitic oxide. J. Am. Chem. Soc. 80, 1339-1339 (1958).

26. Zhu, C. Z., Guo, S. J., Fang, Y. X. \& Dong, S. J. Reducing sugar: new functional molecules for the green synthesis of graphene nanosheets. ACS Nano 4 , 2429-2437 (2010).

27. Graf, D. et al. Spatially resolved raman spectroscopy of single- and few-layer graphene. Nano Lett. 7, 238-242 (2007).

28. Yang, D. X. et al. Chemical analysis of graphene oxide films after heat and chemical treatments by X-ray photoelectron and micro-raman spectroscopy. Carbon 47, 145-152 (2009).

29. Stankovich, S. et al. Synthesis of graphene-based nanosheets via chemical reduction of exfoliated graphite oxide. Carbon 45, 1558-1565 (2007).

30. Wang, D. W., Gentle, I. R. \& Lu, G. Q. Enhanced electrochemical sensitivity of PtRh electrodes coated with nitrogen-doped graphene. Electrochem. Commun. 12, 1423-1427 (2010)

31. Shin, H. J. et al. Efficient reduction of graphite oxide by sodium borohydride and its effect on electrical conductance. Adv. Funct. Mater. 19, 1987-1992 (2009).

32. Sheng, Z. H. et al. Catalyst-free synthesis of nitrogen-doped graphene via thermal annealing graphite oxide with melamine and its excellent electrocatalysis. ACS Nano 5, 4350-4358 (2011).

33. Choi, C. H., Park, S. H. \& Woo, S. I. Heteroatom doped carbons prepared by the pyrolysis of bio-derived amino acids as highly active catalysts for oxygen electroreduction reactions. Green Chem. 13, 406-412 (2011).

34. Chen, C. M. et al. Hierarchically aminated graphene honeycombs for electrochemical capacitive energy storage. J. Mater. Chem. 22, 14076-14084 (2012).

35. Adam, P., Philippe, E. \& Albrecht, P. Photochemical sulfurization of sedimentary organic matter: A widespread process occurring at early diagenesis in natural environments. Geochim. Cosmochim. Acta 62, 265-271 (1998).

36. Amrani, A. \& Aizenshtat, Z. Photosensitized oxidation of naturally occurring isoprenoid allyl alcohols as a possible pathway for their transformation to thiophenes in sulfur rich depositional environments. Org. Geochem. 35, 693-712 (2004).

37. Francois, R. A. Study of sulphur enrichment in the humic fraction of marine sediments during early diagenesis. Geochim. Cosmochim. Acta 51, 17-27 (1987)

38. De Graaf, W., Damsté, J. S. S. \& De Leeuw, J. W. Laboratory simulation of natural sulphurization: I. formation of monomeric and oligomeric isoprenoid polysulphides by low-temperature reactions of inorganic polysulphides with phytol and phytadienes. Geochim. Cosmochim. Acta 56, 4321-4328 (1992).

39. Kohnen, M. E. L., Damsté, J. S. S., Baas, M., Dalen, A. C. K. \& De Leeuw, J. W. Sulphur-bound steroid and phytane carbon skeletons in geomacromolecules: Implications for the mechanism of incorporation of sulphur into organic matter. Geochim. Cosmochim. Acta 57, 2515-2528 (1993).

40. Torma, F., Kádár, M., Tóth, K. \& Tatár, E. Nafion ${ }^{\circledR / 2,2}$ '-bipyridyl-modified bismuth film electrode for anodic stripping voltammetry. Anal. Chim. Acta 619, 173-182 (2008)

41. Sun, C. L., Wang, H. W., Hayashi, M., Chen, L. C. \& Chen, K. H. Atomic-scale deformation in n-doped carbon nanotubes. J. Am. Chem. Soc. 128, 8368-8369 (2006).

42. Terrones, M. et al. N-doping and coalescence of carbon nanotubes: synthesis and electronic properties. Appl. Phys. A: Mater. Sci. Process 74, 355-361 (2002).

\section{Acknowledgments}

The authors would like to acknowledge the financial support received from National Natural Science Foundation of China, (Project No. 51171067, 51173055, 21005023), Natural Science Foundation of Shen Zhen City (Project No. JC201005310696A). 


\section{Author contributions}

P.G., F.X. and S.W. contributed equally. H.L., S.W., Y.G. and J.G. proposed, planned, and designed the project. P.G., F.X. and Q.L. performed the material preparation,

characterizations, and catalytic tests. P.G., F.X., Q.L., H.L., S.W., Y.G., J.G. and Y.L. contributed to writing the manuscript.

\section{Additional information}

Supplementary information accompanies this paper at http://www.nature.com/ scientificreports

Competing financial interests: The authors declare no competing financial interests.

How to cite this article: Guo, P.P. et al. One-Pot Microbial Method to Synthesize Dual-Doped Graphene and Its Use as High-Performance Electrocatalyst. Sci. Rep. 3, 3499; DOI:10.1038/srep03499 (2013)

(c) (i) (2) This work is licensed under a Creative Commons Attribution-

NonCommercial-ShareAlike 3.0 Unported license. To view a copy of this license, visit http://creativecommons.org/licenses/by-nc-sa/3.0 